Pediat. Res. 2: 378-384 (1968)

Cystic fibrosis of

the pancreas

heparin

parotid gland polypeptides

saliva

sodium metabolism

\title{
Studies on the Mechanism of Inhibition of Sodium Transport in Cystic Fibrosis of the Pancreas
}

\author{
J.A.MANGOS ${ }^{[21]}$ and N.R.MaSherry \\ Department of Pediatrics, University of Wisconsin Medical School, Madison, Wisconsin, USA
}

\begin{abstract}
Extract
The saliva of patients with cystic fibrosis of the pancreas (GFP) contains a factor that inhibits sodium reabsorption in the rat parotid gland. The possibility that this factor is a strongly basic macromolecular substance was investigated. Basic polyelectrolytes interact electrostatically with the negatively charged surface of the membrane of a variety of living cells and affect membrane structure and function. Retrograde perfusion of the duct system of the rat parotid was used to study the effect of two natural and three synthetic basic polyelectrolytes on the sodium reabsorption in the rat parotid. Interaction of the luminal side of the parotid duct system with dilute solutions of protamine sulfate, polyethylene imine, arginine-rich histone, polylysine, and polyornithine resulted in significant inhibition of the transductal reabsorption of sodium. Addition of heparin, a strongly negatively charged protein, to the solutions containing the above basic polyelectrolytes resulted in complete elimination of sodium transport inhibitory activity, possibly due to electrostatic interaction and precipitation. Similarly, addition of heparin to the $4: 1$ mixture of saline and saliva from patients with CFP eliminated sodium transport inhibitory activity. It was concluded that the sodium transport inhibitory factor of GFP may be a strongly basic macromolecule that interacts with the cell membrane of transporting epithelia and causes a defect in the reabsorption of sodium in exocrine glands.
\end{abstract}

\section{Speculation}

Sodium transport inhibition has been demonstrated in the rat parotid gland following interaction of the luminal side of the duct system with dilute solutions of natural or synthetic basic polyelectrolytes. This activity of the above solutions disappears following the addition of heparin, a negatively charged protein. Similarly, heparin eliminates the sodium transport inhibitory activity of saliva from patients with CFP. This, admittedly indirect, evidence suggests that the sodium transport inhibitory factor in the saliva of patients with CFP may be a strongly basic macromolecule and opens new directions in the search for the molecular defect of CFP. 


\section{Introduction}

The sweat, mixed mouth saliva and parotid saliva of patients with cystic fibrosis of the pancreas (CFP) have higher sodium and chloride concentrations than the same excretory fluids of normal children [3]. This abnormality has been attributed to a defect in the reabsorption of sodium and chloride in the duct systems of the corresponding glands [3]. Recently, we proposed that this defect may be due to a sodium transport inhibitory factor that is present in the excretory products of these glands $[10,11]$. We proceeded to demonstrate that sweat and saliva of patients with CFP contain a factor that inhibits sodium reabsorption in the rat parotid when the duct system of the gland is perfused with one of these excretory products for a brief period of time. During these experiments, it became clear that sweat and saliva from patients lost transport inhibitory activity when stored in glass containers. Since it is known that glass interacts electrostatically with strongly positively charged polyamino acids and removes them from their solutions [5], we investigated the possibility that the sodium transport inhibitory factor of CFP may be a positively charged macromolecular substance.

Basic macromolecular substances such as basic proteins, polyamino acids, polypeptides, and organic polyelectrolytes have been shown to have profound effects on a wide variety of living cells. Polylysine decreases the virulence of tobacco mosaic virus [2], agglutinates bacteria [6] and chicken erythrocytes [14], and agglutinates and hemolyzes human erythrocytes [5, 13]. Protamine and polyethylene imine affect viability and decrease the size of experimental tumors $[1,12]$. Histones, basic polyamino acids, and DEAE-dextran increase the uptake of albumin and ferritin by tumor cells in cultures [16]. Positively charged polymers were demonstrated to interact with the negatively charged surface of human erythrocytes $[5,13]$. This interaction appeared to be mainly due to nonspecific ionic electrostatic forces. Electron microscopical study of erythrocyte ghosts treated with polylysine showed marked changes in membrane texture. It appears that these compounds affect living cells by action on the cell membrane with a threshold of activity in the range of $10^{-10} \mathrm{M}$, which is comparable to the activities of the most potent membrane-active agents. We have studied the effects of various basic polyelectrolytes on the reabsorption of sodium by the duct system of the rat parotid gland.

In this study, we demonstrated that retrograde perfusion of the duct system of the rat parotid gland with buffered saline containing one of several basic macromolecular compounds resulted in marked inhibition of transductal reabsorption of sodium. The compounds used in this study were of different chemical composition (basic proteins, polyamino acids, and organic polyelectrolytes) but shared one common characteristic, strong positive charges on a large molecule. Addition of the negatively charged substance heparin to solutions containing the above polycations resulted in elimination of sodium transport inhibitory activity. Similarly, addition of heparin to the saliva of patients with CFP resulted in elimination of the transport inhibitory effect. It was concluded that the sodium transport inhibitory factor may be a strongly positively charged macromolecule which interacts with the cell membrane of the transporting cells of exocrine glands and causes a decrease in the transductal reabsorption of sodium. This defect in reabsorption may in turn result in the higher concentrations of sodium in the sweat and saliva of patients with GFP.

\section{Material and Methods}

Patients with CFP were among those followed at the Cystic Fibrosis Clinic of the Medical Center of the University of Wisconsin. They had the symptoms and signs of the disease and the diagnosis was confirmed by the presence of increased concentrations of sodium and chloride in sweat collected following iontophoresis of the skin with pilocarpine. Saliva was collected from the patients by the method described in a previous report [10].

In the present experiments, we investigated changes in sodium reabsorption produced by perfusion of the duct system of the rat parotid for 90 seconds with a $0.9 \% \mathrm{NaCl}$ solution (buffered to $\mathrm{pH} 7.3$ with sodium phosphate) containing one of the positively charged substances, protamine sulfate, polyethylene imine, arginine-rich histone, polylysine, or polyornithine. Subsequently, we studied the effect of addition of heparin to solutions containing some of the above polyelectrolytes. Finally, we investigated the effects of heparin on the sodium transport inhibitory activity of saliva from patients with GFP.

Male albino rats of the Sprague-Dawley strain were anesthetized with pentobarbital $(8 \mathrm{mg} / 100 \mathrm{~g}$ body weight) injected intraperitoneally. Following retrograde perfusion of the duct system of the parotid as previously described [8], we stimulated the gland to secrete saliva with pilocarpine $(0.1 \mathrm{mg} / 100 \mathrm{~g}$ body weight), injected intravenously. Although the entire duct system of the gland was perfused, we interpreted our observations to be effects on the striated ducts, since the bulk of sodium reabsorption occurs in these ducts. The rate of sodium reabsorption was calculated as described in a previous publication [10] by measuring the concentrations of sodium in the fluid secreted 
by the acini-intercalated ducts of the gland and in the final saliva. Fluid from the intercalated ducts was obtained by micropuncture of these structures and final saliva by cannulation of the main parotid duct with a fine polyethylene tube. The methods of micropuncture, collection of samples, and microanalysis have been described previously $[8,9,10]$. The rate of sodium reabsorption was expressed as $\mu \mathrm{Eq} / \mathrm{min} / \mathrm{g}$ wet gland tissue. The basic polyelectrolytes used in these experiments were: Polylysine (poly-L-lysine HBr, M.W. 195,000); Polyornithine (poly-L-ornithine HBr, M.W. 150,000); Polyethylene imine $\left[\left(-\mathrm{CH}_{2}-\mathrm{CH}_{2}-\mathrm{NH}\right)_{\mathrm{n}}, \mathrm{M}\right.$.W. 70,000-80,000]; Histone (arginine-rich from calf thymus); and Protamine Sulfate (Grade I, from salmon) [19]. The sodium salt of heparin was used [20].

\section{Results}

Transductal Reabsorption of Sodium in the Rat Parotid Following Retrograde Perfusion of the Duct System

As shown on table I, perfusion of the duct system of the rat parotid with a buffered $0.9 \% \mathrm{NaCl}$ solution had no effect on the reabsorption of sodium. Thus, it was established that the experimental procedure itself did not affect the transporting capacity of the striated ducts. Perfusion of the gland with saline containing protamine sulfate, a basic protein, resulted in a significant decrease in the rate of sodium reabsorption. Polyethylene imine, a strongly positive ionic polyelectrolyte, in concentrations of $10^{-6} \mathrm{M}$ caused an even greater inhibition of sodium reabsorption. Arginine-rich histone, a basic protein from calf thymus, decreased the reabsorption of sodium by $64.5 \%$. The most pronounced inhibitory effect, $81.5 \%$, was exerted by the synthetic polyamino acid, polylysine, in concentrations of $10^{-6} \mathrm{M}$. In concentrations of $10^{-7} \mathrm{M}$, the degree of inhibition was only $49.8 \%$ of that of the control. When the concentration of polylysine in the perfusate was reduced to $10^{-8} \mathrm{M}$, or less, no inhibition of sodium reabsorption was observed. Similarly, polyornithine had a marked inhibitory effect at concentrations of $10^{-6}$ and $10^{-7} \mathrm{M}$, minimal activity at $10^{-8} \mathrm{M}$, but no activity at $10^{-9} \mathrm{M}$.

\section{Effect of the Addition of Heparin to the Buffered Saline} Containing Polylysine, Polyethylene Imine, and Arginine-Rich Histone

As shown on figures 1, 2, and 3, retrograde perfusion of the rat parotid with a solution containing polylysine or polyethylene imine or arginine-rich histone resulted in excretion of saliva that contained higher concentrations of sodium than did the saliva of the control animal at any given flow rate. In duplicate experiments, 500 units of heparin sodium were added to each of the solutions containing the above polycationic compounds prior to retrograde perfusion. As shown in figures 1,2 , and 3 , the addition of heparin eliminated the inhibitory effect of these compounds on the reabsorption of so-

Table $I$. The rate of transductal reabsorption of sodium in the parotid gland of rats before and after retrograde perfusion of the duct system of the gland with buffered saline ( $\mathrm{pH}$ 7.3) containing basic proteins and polymers. The rates of sodium reabsorption have been calculated as described in a previous report [10] and represent the average values at salivary flow rates from $30-100 \mu \mathrm{l} / \mathrm{min} / \mathrm{g}$ wet gland tissue. Time of perfusion: 90 seconds.

\begin{tabular}{lll}
\hline & $\begin{array}{l}\text { No. of } \\
\text { determinations }\end{array}$ & $\begin{array}{l}\text { Rate of Na } \\
\text { reabsorption } \\
(\mu \mathrm{Eq} / \mathrm{min} / \mathrm{g} \text { of gland })\end{array}$ \\
\hline 1. Control (no retrograde perfusion) & 162 & $6.01 \pm \mathrm{SD} 0.83$ \\
2. Retrograde perfusion with 0.9\% $\mathrm{NaCl}$ solution & 72 & $5.94 \pm \mathrm{SD} 1.07$ \\
3. Retrograde perfusion with protamine sulfate $(300 \mu \mathrm{g} / \mathrm{ml})$ & 25 & $2.51 \pm \mathrm{SD} 0.61^{*}$ \\
4. Retrograde perfusion with polyethylene imine $\left(10^{-6} \mathrm{M}\right)$ & 31 & $1.53 \pm \mathrm{SD} 0.85$ \\
5. Retrograde perfusion with histone arginine-rich $(300 \mu \mathrm{g} / \mathrm{ml})$ & 36 & $2.13 \pm \mathrm{SD} 0.81^{*}$ \\
6. Retrograde perfusion with polylysine $\left(10^{-6} \mathrm{M}\right)$ & 38 & $1.11 \pm \mathrm{SD} 0.39^{*}$ \\
7. Retrograde perfusion with polylysine $\left(10^{-7} \mathrm{M}\right)$ & 30 & $3.02 \pm \mathrm{SD} 1.31^{*}$ \\
8. Retrograde perfusion with polylysine $\left(10^{-8} \mathrm{M}\right)$ & 34 & $5.64 \pm \mathrm{SD} 2.62$ \\
9. Retrograde perfusion with polyornithine $\left(10^{-6} \mathrm{M}\right)$ & 26 & $1.32 \pm \mathrm{SD} 0.41^{*}$ \\
10. Retrograde perfusion with polyornithine $\left(10^{-7} \mathrm{M}\right)$ & 23 & $3.57 \pm \mathrm{SD} 1.63^{*}$ \\
11. Retrograde perfusion with polyornithine $\left(10^{-8} \mathrm{M}\right)$ & 16 & $4.69 \pm \mathrm{SD} 1.96$ \\
12. Retrograde perfusion with polyornithine $\left(10^{-9} \mathrm{M}\right)$ & 19 & $5.86 \pm \mathrm{SD} 1.76$ \\
\hline
\end{tabular}

* Statistically significant difference from controls $(p<0.001)$ 


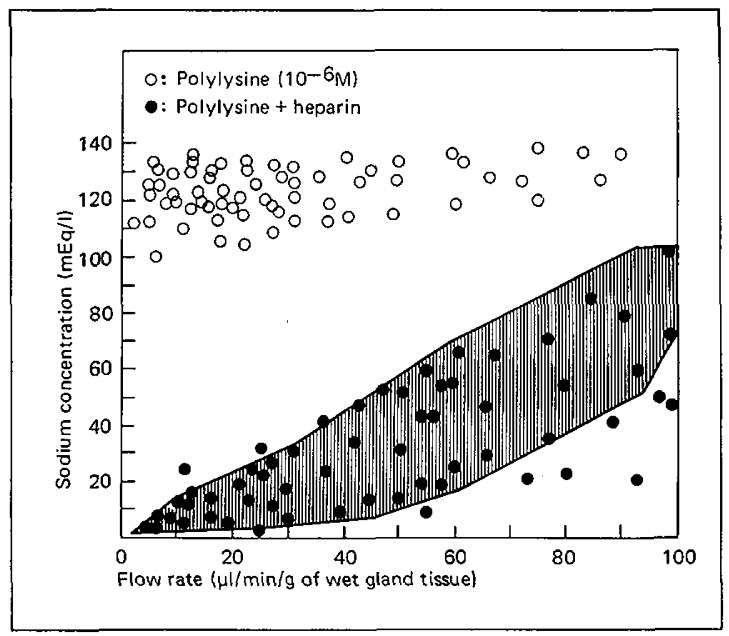

Fig. 1. The relation between sodium concentration and flow rate in the rat parotid following retrograde perfusion of the duct system of the glands (10 rats) with buffered saline (shaded area representing the range of measurements) saline containing polylsyine (open circles), and polylysine plus heparin, 500 units per $\mathrm{ml}$ (dark circles).

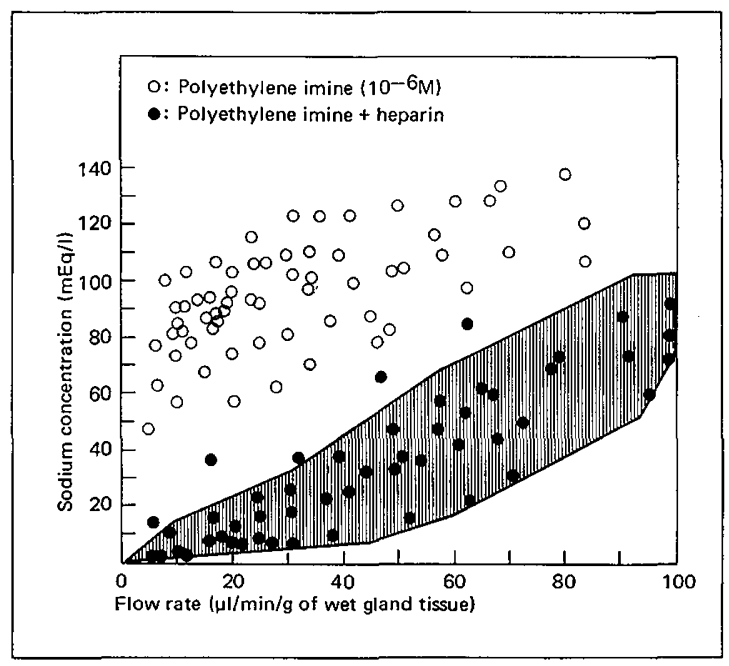

Fig. 2. The relation between sodium concentration and flow rate in the rat parotid saliva following retrograde perfusion of the duct system of the glands (10 rats) with buffered saline (shaded area representing the range of measurements), saline containing polyethylene imine (open circles) and polyethylene imine plus heparin, 500 units per $\mathrm{ml}$ (dark circles).

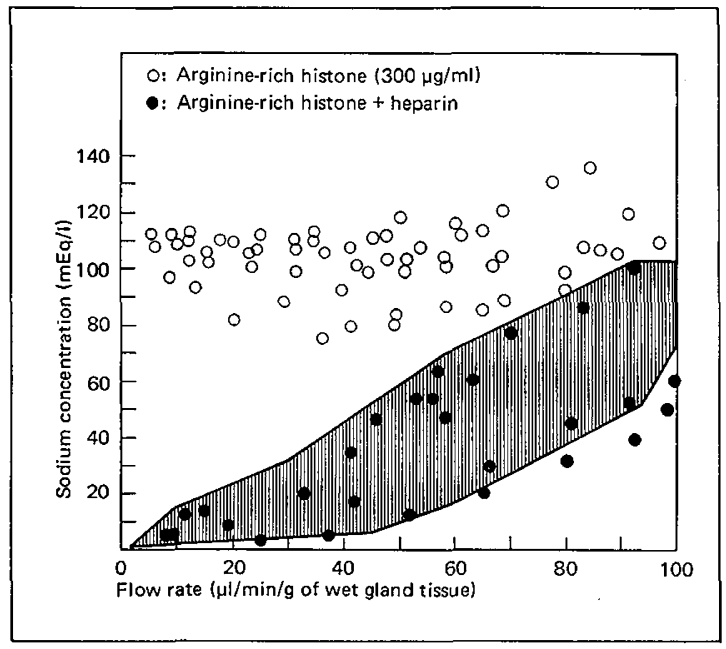

Fig. 3. The relation between sodium concentration and flow rate in the rat parotid saliva following retrograde perfusion of the duct system of the glands for 10 rats with buffered isotonic saline (shaded area representing the range of measurements), saline containing argininerich histone (open circles) and arginine-rich histone plus heparin, 500 units per $\mathrm{ml}$ (dark circles).

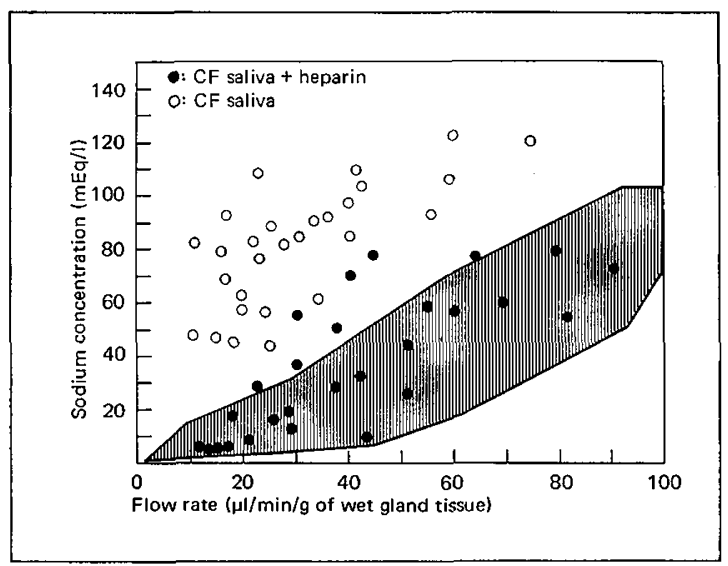

Fig.4. The relation between sodium concentration and flow rate in the rat parotid saliva following retrograde perfusion of the duct systems of the glands of 10 rats with buffered isotonic saline (shaded area representing the range of measurements), a 4:1 mixture of saline and saliva from patients with GFP (open circles) and the same mixture, after the addition of heparin, 500 units per $\mathrm{ml}$ (dark circles). 


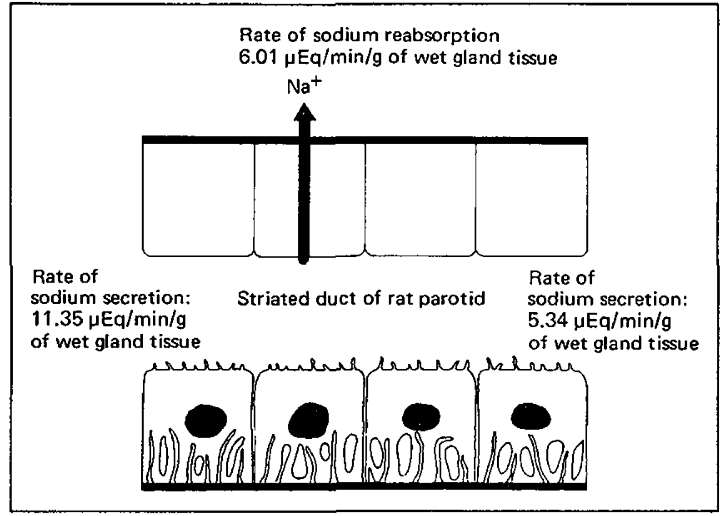

Fig.5. A diagram of the striated duct of the rat parotid showing the movements of sodium at the hypothetical flow rate of $80 \mu \mathrm{l} / \mathrm{min} / \mathrm{g}$ wet gland tissue (for detailed description see text).

dium by the rat parotid. This resulted in concentrations of sodium in the saliva which were identical to those of the control rats.

\section{Effects of the Addition of Heparin to Saliva from Patients with CFP}

As we have shown previously, retrograde perfusion of the duct system of the rat parotid with a 4:1 mixture of isotonic saline and saliva from patients with CFP resulted in a marked increase in the sodium concentrations of saliva at any given flow rate. Addition of heparin to the mixture of saline and saliva (500 units $/ \mathrm{ml}$ ) prior to retrograde perfusion resulted in complete elimination of the sodium transport inhibitory effect (fig. 4).

\section{Discussion}

In a previous study, we demonstrated that saliva of patients with GFP contains a factor that inhibits the transductal sodium reabsorption in the rat parotid gland following interaction with the luminal side of the membrane of the transporting cells. The present study demonstrates that similar interaction of various basic polyelectrolytes with the membrane of the duct cells causes inhibition of sodium reabsorption. Furthermore, addition of heparin to saliva from patients with CFP and to solutions of the basic macromolecular compounds resulted in elimination of inhibitory activity. It was concluded that the sodium transport inhibitory factor may be a positively charged macromolecular substance which interacts with the cell membrane and causes an alteration in its structure and/or function.
As we have shown recently $[8,9]$, the rat parotid excretes saliva hypotonic to plasma. The primary fluid secreted by the acini-intercalated ducts of the gland has osmolarity and concentrations of sodium and potassium identical with those of plasma. Salivary hypotonicity is produced by reabsorption of sodium in excess of water as the primary fluid flows along the duct system of the gland. Over $98 \%$ of sodium reabsorption takes place in the striated ducts. These ducts, when examined by light or electron microscopy [11], are lined with one layer of cells which are similar to the cells lining the distal tubule of the mammalian nephron (fig.5). The plasma membrane of the luminal side of these cells has a small number of microvilli; on the contraluminal side, the membrane forms deep invaginations surrounding numerous mitochondria. The infoldings of the membrane and the mitochondria give the striated appearance to these cells. The mechanism of sodium reabsorption across the wall of the striated ducts is not clear. It is possible that sodium enters the cells on the luminal side along a concentration gradient and is subsequently transported actively across the contraluminal side into the interstitium. It is also possible that active uptake of sodium from the duct fluid takes place at the luminal side of the cells. This would be followed by active extrusion of sodium across the contraluminal side into the interstitium. In either case, the luminal side of the cells is the structure that comes in contact with the duct fluid. Alterations in the structure or function of this membrane may result in changes in sodium reabsorption by the striated ducts.

The effects of basic polyelectrolytes are viewed as the result of interaction with the surface of the cell membrane. In these experiments, the perfusing solution came in contact with the luminal side of the cells lining the striated ducts. Although we cannot exclude the possibility that leakage of the perfusate through the intercellular spaces may have brought these basic compounds in contact with the plasma membrane of the contraluminal side of the cells, we believe that the major contact must have occurred on the luminal side of the membrane. The studies of Nevo et al. [13] indicate that these substances act on the surface of the cell membrane and because of their large molecular size, they do not enter the cells. Recently, Wissig et al. [17] showed by electron microscopy that the mucosal surface membrane of the superficial epithelial cells of the toad bladder became dense and markedly thickened after exposure to dilute solutions of polylysine. The unit membrane structure had, for the most part, disappeared. In parallel experiments, these investigators demonstrated that exposure of the mucosal side of the toad bladder to polylysine caused a marked fall in the potential difference and the short circuit current. 
We view the effects of these basic compounds on the sodium reabsorption of the rat parotid as the result of interaction of these substances with the surface of the plasma membrane of the cells lining the straited ducts which is the first barrier in the reabsorption of sodium. The nature of the interaction between these basic compounds and the cell membrane is not known. Recently, however, studies of the membrane protein conformation by optical rotatory dispersion and circular dichroism demonstrated that a significant part of the cell membrane protein is in $\alpha$-helical form [7]. It was suggested that some of the helical segments of the protein molecule reach into the lipid layers of the membrane, while other segments are located on the membrane surface which is negatively charged. Polybasic compounds interacting with the negative end groups of the cell surface by multiple electrostatic attachments may influence the conformation of membrane proteins by changing the charge distribution on segments of peptide chains. RYSER [16] has suggested that multiple attachment of a basic polymer to neighboring points of the membrane could strain the membrane structure. One long chain polymer could be expected to interact with several structural proteins and to have profound effects on membrane structure and function. With the exception of the various histones, otherstrongly basic substances have not been demonstrated in man and mammals. Since, however, these agents are active in very small concentrations and tend to interact with the cell surface, it is possible that they play a role in the regulation of cell membrane permeability at the cellular level without being detected in body fluids or tissue homogenates. In addition, as KATchaLsKy et al. [5] observed with polylysine, these polymers tend to adhere to the glass surface and to be removed from solutions when the latter are placed in glass containers. The above characteristic features of these basic compounds may have interfered with their detection in or isolation from biological fluids. It is also possible that in diseases of man and animals affecting membrane permeability, the production of such positively charged substances may be the underlying cause of alterations in membrane structure and/or function.

Heparin is a strongly negatively charged (acidic) protein. KatchaLsky [4] has shown that basic polyelectrolytes in solutions interact with acidic polyelectrolytes electrostatically with precipitation at the point of polymeric electroneutrality. In our experiments, the addition of heparin to solutions containing the polyelectrolytes studied apparently resulted in electrostatic bonding and precipitation of the active macromolecules. Similar elimination of the sodium transport inhibitory activity observed following the addition of heparin to saliva from patients with CFP may be considered indirect evidence that the sodium transport inhibitory factor in this disease is a basic macromolecular substance. We propose, therefore, that cystic fibrosis of the pancreas may be a disease in which transductal reabsorption of sodium in the sweat and salivary glands is partially inhibited because of the effects of interaction of a basic macromolecular substance with the cell membrane of the transporting cells. This would result in increased sodium concentrations in the final excretory products. It is possible that the same substance may be responsible for the abnormality of mucus in CFP either directly, by affecting the solubility of mucus substances, or indirectly, by affecting the ionic composition of exocrine gland products which in turn would affect the solubility of mucus.

\section{References and Notes}

1. Ambrose, E.J.; EAsty, D. M. and Jones, P.C.T.: Specific reactions of polyelectrolytes with the surfaces of normal and tumor cells. Brit. J. Cancer 12: 439 (1958).

2. Burger, L.W. G. and Stahmann, M.A.: The combination of lysine polypeptides with tobacco mosaic virus. J. biol. Chem. 193: 13 (1951).

3. Di Sant'Agnese, P.A. and Talamo, R. G.: Pathogenesis and physiopathology of cystic fibrosis of the pancreas. New Engl.J. Med. 277: 1287 (1967).

4. Katchalsky, A.: Polyelectrolytes and their biological interactions. Biophys. J. 4: 9 (1964).

5. Katchalsky, A.; Damon, D.; Nevo, A. and De VRIES, A. : Interactions of basic polyelectrolytes with the red blood cell. II. Agglutination of red blood cells by polymeric bases. Biochim. biophys. Acta 33: 120 (1959).

6. Katchalsky, E.; Bighovsky, L. and Volcani, E. B.: The action of some water soluble poly-2amino acids on bacteria. Biochem. J. 55: 671 (1953).

7. Lenard, J. and Singer, S. J. : Protein conformation in cell membrane preparations as studied by optical rotatory dispersion and circular dichroism. Proc. nat. Acad.Sci., Wash. 56: 1828 (1966).

8. Mangos, J.A. and Braun, G.: Excretion of total solute, sodium and potassium in the saliva of the rat parotid gland. Pfügers Arch. ges. Physiol. 290: 184 (1966).

9. Mangos, J.A.; Braun, G. and Hamann, K.F.: Micropuncture study of sodium and potassium excretion in the rat parotid saliva. Pflügers Arch. ges. Physiol. 291: 99 (1966).

10. Mangos, J.A.; McSherry, N.R. and Benke, P.J.: A sodium transport inhibitory factor in the saliva of patients with cystic fibrosis of the pancreas. Pediat.Res. 1: 436 (1967). 
11. Mangos, J.A. and MaSherry, N.R.: Sodium transport: inhibitory factor in sweat of patients with cystic fibrosis. Science 158: 135 (1967).

12. Muggleton, P.U.; Malaren, J. and Dyke, W.J.C.: Effect of protamine sulphate on experimental tumors in mice. Lancet $i$ : 409 (1964).

13. Nevo, A.; DeVries, A. and Katchalsky, A.: Interaction of basic polyamino acids with the red blood cell. Biochim. biophys. Acta 17: 536 (1955).

14. Rubini, J.R.; Stahmann, M.A. and Rasmussen, A.F., Jr.: Agglutination of red cells by synthetic lysine polypeptides. Proc. Soc. exp. Biol., N.Y. 76: 659 (1951).

15. RUTBERG, U.: Ultrastructure and secretory mechanism of the parotid gland. Acta odont. scand. 19; suppl. 30 (1961).

16. RYSER, H.J.-P.: Uptake of protein by mammalian cells: an underdeveloped area. Science 159: 390 (1968).

17. Wissig, S.; Mamelax, M. and Edelman, I. S.: The effects of polylysine on the structure and function of the toad bladder. Abstracts. First Annual Meeting of the Amer. Soc. of Nephrology, October 18-19, p. 71 (1967).

18. Supported by Grant A.M.-06365 from the N.I.A. M.D. and by the National Cystic Fibrosis Research Foundation.

19. Purchased from Sigma Chemical Company, St. Louis, Missouri.

20. Obtained from Eli Lilly Company, Indianapolis, Indiana.

21. Requests for reprints should be addressed to Јонм A. Mangos, M.D., Department of Pediatrics, University of Wisconsin Medical Center, 1300 University Avenue, Madison, Wis. 53706 (USA). 